\title{
AMBIENTALISMO.COM: a atuação do movimento ambientalista diante as novas mídias digitais - uma análise a partir das campanhas do Greenpeace e Avaaz
}

\author{
Mariana Cunha Maroneze ${ }^{1}$ \\ Mariana Fenalti Salla ${ }^{2}$ \\ Rafael Santos de Oliveira ${ }^{3}$
}

\begin{abstract}
Resumo: A participação dos movimentos ambientalistas como agentes de mudança no cenário mundial foi fortalecida nas últimas décadas. Para o sucesso das campanhas promovidas em prol do meio ambiente por tais agentes, a Internet tem sido uma importante ferramenta. Através dela, cidadãos de todos os continentes agregam-se em torno de uma causa comum, funcionando como receptores e transmissores de informações e iniciativas, e exercendo o que se chama de ciberativismo ou ativismo digital. O presente artigo procura investigar de que maneira o ativismo digital auxilia na atuação dos movimentos ambientalistas, especialmente através da análise das campanhas e petições online promovidas pelo Greenpeace e pelo Avaaz.
\end{abstract}

Palavras-chave: Ciberativismo. Movimento ambientalista. Greenpeace. Avaaz.

\section{INTRODUÇÃO}

A capacidade de modificação do meio ambiente, apesar de ter garantido a sobrevivência humana em seu processo evolutivo, atualmente, ameaça a sua existência na Terra. Por muito tempo a consciência do risco e dos danos que essas ações antrópicas poderiam causar foi ignorada pelo homem. A percepção de que os modos de produção capitalista necessitavam ser repensados, visando atingir uma relação mais harmoniosa do homem com a natureza, somente emergiu no final dos anos 1960. A partir desse momento emergiram diversos movimentos ambientalistas preocupados em reverter essa situação e em demonstrar à opinião pública mundial os riscos que a inércia por parte dos governantes e da sociedade civil poderia trazer ao meio ambiente.

\footnotetext{
${ }^{1}$ Acadêmica do Curso de Direito da Universidade Federal de Santa Maria. Pesquisadora do Núcleo de Direito Informacional, vinculada ao projeto de pesquisa intitulado Ativismo digital e as novas mídias: desafios e oportunidades da cidadania global. email: marianamaroneze@ gmail.com

2 Acadêmica do Curso de Direito da Universidade Federal de Santa Maria. Pesquisadora do Núcleo de Direito Informacional, vinculada ao projeto de pesquisa intitulado Ativismo digital e as novas mídias: desafios e oportunidades da cidadania global. email: sallamariana@gmail.com

3 Professor Adjunto do Departamento de Direito da Universidade Federal de Santa Maria

Doutor em Direito pela Universidade Federal de Santa Catarina (UFSC). Pesquisador do Núcleo de Direito Informacional, orientador do projeto de pesquisa intitulado Ativismo digital e as novas mídias: desafios e oportunidades da cidadania global. email: advrso@gmail.com
} 
Foi nesse momento de luta pela preservação ambiental que surgiram diversas Organizações Não governamentais (ONGs) preocupadas com a causa ambiental e que buscavam incluir tal temática nas discussões políticas internacionais. Gradualmente, passaram a gozar de reconhecimento e prestígio político, razão pela qual puderam a partir da década de 70 dar voz a causas ecológicas e conscientizar a sociedade civil da importância de se preservar o meio ambiente. Para alcançar tais objetivos, dentre outras estratégias, essas organizações buscavam adquirir visibilidade social, o que se dava, inicialmente, pela cobertura da mídia tradicional (rádio, TV e jornal). Até os dias de hoje, tal estratégia ainda é adotada pelas ONGs ambientalistas, contudo, com uma ampliação nos meios empregados. Graças à recente popularização das mídias digitais o movimento ambientalista ganhou espaço junto ao mundo virtual e ampliou o número de apoiadores de sua causa. O surgimento do ciberativismo ambiental permitiu um maior fluxo informacional e uma ampliação significativa da luta por direitos, divulgação de causas e a busca por conscientização através da Internet.

Diante desse contexto, o presente artigo pretende investigar de que maneira o ativismo digital auxilia na atuação dos movimentos ambientalistas, especialmente através da análise das campanhas e petições online promovidas pelo Greenpeace e pelo Avaaz. Para tanto, o artigo foi elaborando empregando o método de abordagem dedutivo, partindo de uma análise geral sobre as mídias até chegar a uma análise específica sobre as duas entidades. Como método de procedimento, foi utilizada a observação direta dos sites do Greenpeace e Avaaz realizando-se uma análise comparativa entre ambos, além da revisão bibliográfica em torno das organizações não governamentais e do desenvolvimento e evolução do movimento ambientalista.

Diante disso, o artigo foi organizado em duas partes: na primeira, são analisadas as facilidades que as novas mídias trazem ao movimento ambientalista; na segunda, a forma de atuação das duas entidades específicas e quais foram os resultados obtidos pelas suas iniciativas promovidas no espaço virtual.

\section{0 ciberativismo ambiental: uma alternativa de atuação inovadora para o movimento ambientalista}


$\mathrm{O}$ ambientalismo pode ser entendido como um movimento social que possui diversas correntes cujo vértice é, em termos gerais, a preocupação com o meio ambiente e o desejo de preservação de todos os organismos vivos. Leff (2007) destaca que, muito embora tenham uma enorme diversidade ideológica e praxeológica, os movimentos ambientais:

\begin{abstract}
Caracterizam-se por sua composição pluralista e pela heterogeneidade de seus atores sociais que vão conformando alianças em torno de objetivos comuns: a sobrevivência da espécie humana,a conservação da natureza, a diversidasde étnica, a auto-suficiência alimentar, a seguridade social, o equilíbrio ecológico, a qualidade de vida e a participação comunitária na gestão dos recursos. ( LEFF, 2007, p. 113)
\end{abstract}

Nesse contexto, inserem-se como atores de mudança todas as instituições, organizações não governamentais, ativistas independentes e até mesmo partidos políticos que possuam como propósitos a conservação do ecossistema e o desenvolvimento sustentável. Tais atores, por muitos anos, tentaram difundir suas ideias através dos meios de comunicação tradicionais. Entretanto, esses não permitiram sua plena difusão, devido a alguns fatores que dificultariam a sua atuação: altos custos, concessão governamental, verticalidade e centralização na transmissão de informações, dentre outros.

Ao analisar esses entraves, Pinto e Fossá (2011, p. 27) destacam que "As minorias [...] necessitam estar presentes nos meios de comunicação de massa", justificando que somente assim conseguem legitimar o seu discurso. Contudo, o problema é que a "acessibilidade aos referidos meios de comunicação não é democrática como resultado dos filtros ideológicos e mercadológicos da mídia" (PINTO; FOSSÁ, 2011, p. 27).

A Internet, por sua vez, propicia uma alteração nesse cenário, pois os ciberativistas podem criar suas próprias páginas, divulgar a informação que julgarem mais relevante sem passar pelo crivo de uma comissão editorial e sem depender de fomentos financeiros de empresas. O advento das novas tecnologias e da Internet, “acessíveis, fáceis de usar e gratuitas” (LEMOS e LÉVY, 2010, p. 107), constituiu-se um divisor de águas que permitiu a rápida expansão e plena atuação daqueles engajados nas causas ambientais - ciberativistas.

Desse modo, tendo domínio sobre as matérias que serão publicadas e dispondo dos novos recursos multimídia que a Internet proporciona, os ativistas ambientais 
podem exercer plenamente seu papel de popularizadores dos problemas ambientais, conferindo-lhes relevância, familiaridade e expondo-os com linguagem acessível.

Segundo Solesbury (1976) e Hannigan (2009), ações necessárias ao se construir um problema ambiental seriam atrair a atenção, legitimar o problema, dramatizá-lo visualmente e invocar a ação.

A atenção tem sido atraída por movimentos fomentados pelas ONGs na Internet, mídia que possibilita catalisar forças políticas singulares e transformar suas ideias em ações globais. Exemplo foi o ato chamado "Wake up call", proposto pela comunidade Avaaz, o qual foi composto por mais de 2600 manifestações em mais de 135 países e alcançou o intento de capturar a atenção, tendo em vista que foi noticiado em jornais renomados através do mundo. (AVAAZ, 2012)

Para legitimar o problema, os ativistas podem inserir livremente demonstração de evidências científicas e argumentos de autoridades em seus textos, tendo em vista que na Internet o espaço para publicação é ilimitado, diferentemente das mídias impressas.

A gama de recursos multimídia ofertados na Internet permite a dramatização do problema. Vídeos, depoimentos da população localmente atingida por determinado problema e "imagens provocam uma espécie de atalho cognitivo, transformando um argumento complexo em um que é facilmente compreensível” (HANNIGAN, 2009, p.118), permitindo que o público abstraia a dimensão do perigo.

A interação que a internet gera oportuniza que a ação seja invocada principalmente por meio das petições online. Essa ferramenta, apesar de não ser um dispositivo que surta consequências legais diretas, baseia-se na convicção de que "o consenso do apoio público não só pode marcar o crescimento de um problema, mas também pode constituir um recurso valioso no esforço de capturar a atenção política" (HANNINGAN, 2009, p.115). Assim, entidades têm organizado a coleta de assinaturas, de modo a corroborar uma causa e reivindicar mudanças.

Além dessas facilidades, a grande vantagem do Ciberativismo via petições online é a dimensão global que a causa pode atingir, ao passo que as mídias tradicionais se restringem a um público local. De acordo com Brianna Cayo Cotter, integrante do Avaaz (constituído por mais de 15 milhões e meio de colaboradores em 194 países), é preciso saber aproveitar potencial de divulgação da internet tendo em vista que "só a 
web é capaz de mobilizar tanta gente a ponto de realmente obter mudanças" (ECODESENVOLVIMENTO, 2011)

O Ciberativismo ambiental também é capaz de conciliar duas noções de tempo que são antagônicas, na medida em que adota um paradigma glacial e intertemporal em relação ao meio ambiente. Isso significa dizer que o movimento ambientalista que atua por meio da Internet vislumbra a natureza a partir de uma noção de tempo de longo prazo, ao passo que reconhece que "qualquer alteração nos mecanismos básicos do planeta, e do universo, poderá, ao longo do tempo, desfazer um delicado equilíbrio ecológico, trazendo consequências desastrosas." (CASTELLS, p. 158). Da mesma forma, o movimento ambientalista milita em tempo real, através da elaboração de campanhas que chamam a atenção para temáticas globais específicas.

As mídias digitais conseguem obter, como nenhum outro meio de comunicação massivo, um impacto de grande dimensão em relação a problemas ambientais pontuais. Isso porque a cibermilitância rompe barreiras geográficas e transmite informações instantaneamente, de modo que pessoas de qualquer parte do mundo, em poucos segundos, tomam conhecimento das denúncias realizadas pelos movimentos sociais ambientalistas sem nenhum custo financeiro. Assim, cidadãos de diferentes nacionalidades conseguem articular-se por meio da rede virtual, e aquilo que, à primeira vista parecia uma preocupação local, começa a tomar contornos de nível global.

Ademais, o ativismo na Internet remete a uma noção de espaço democrático de discussão sobre direitos coletivos, pois auxilia na formação de coalizões de pessoas que, individualmente, não fariam eclodir as suas opiniões e ideias. Richard Barbrook (2000), por sua vez, chega a considerar que a Internet faz reviver certos ideais comunistas, ao permitir a tomada dos meios de produção de comunicação pelos desfavorecidos e marginalizados e por favorecer uma formação cívica mais consistente.

Igualmente, o ciberativismo foge da visão totalizante da mídia tradicional, que viabiliza voz a poucos emissores. Tal fato é relevante, sobretudo quando está em jogo a causa ambiental, porque os atores interessados na disseminação de ideias e intercâmbio de reflexões podem, através da Internet, contestar as forças hegemônicas e driblar o monopólio de divulgação de um jornalismo que não possui compromisso sério com o meio ambiente. 
O espaço virtual, portanto, consolidou-se como a plataforma ideal para os movimentos sociais ambientalistas, pois oportuniza que cidadãos comuns de todo o mundo possam ter acesso às campanhas e informações que envolvem a problemática ambiental. Isso se dá, justamente, pelas facilidades que a Web proporciona em relação às mídias tradicionais (baixo custo, disseminação de notícias em nível global, inexistência de filtros que necessitem autorizar a divulgação de matérias) e pela capacidade que a plataforma digital tem de agregar cidadãos em torno daquilo que se chama ativismo digital.

Dentro de um cenário que denota a pluralidade de vantagens na utilização da Internet, percebe-se que uma grande parcela das organizações não governamentais e outras entidades que lutam pela causa ambientalista estão, com uma frequência cada vez maior, promovendo campanhas que se valem da plataforma digital para mobilizar a opinião pública. Para investigar o alcance e efetividade das campanhas virtuais, especialmente das petições online, o próximo ponto estabelece uma análise comparativa entre a maior organização não governamental que luta pelo meio ambiente (Greenpeace) e a maior comunidade global sem fins lucrativos que estrutura campanhas online (Avaaz).

\section{A estratégia adotada pelo Greenpeace e pelo Avaaz na defesa das causas}

\section{ambientais}

É impossível, hoje, quando se trata de repercussão de problemáticas ambientais, deixar de lembrar da atuação das organizações não-governamentais, na medida em que estas, há décadas, tornaram-se agentes sociais de grande relevância para consolidar, no cenário mundial, a preocupação com o meio ambiente.

A característica essencial de uma ONG é o fato de ser ela uma associação ou fundação que não possui finalidade lucrativa, justamente porque possui o escopo de "influenciar ou corrigir a atuação dos sujeitos de direito internacional, especialmente os Estados soberanos e as organizações internacionais.” (LEÃO, 2002) .

As organizações não governamentais que atuam na defesa do meio ambiente possuem, em geral, uma metodologia semelhante para pressionar os sujeitos de Direito Internacional a adotarem uma postura de defesa do meio ambiente e políticas públicas que priorizem o desenvolvimento sustentável. 
internacional, é a manifestação da emergência de uma sociedade civil, também internacional, global” (LEÃO, 2002).

A entidade, por exemplo, decidiu fazer uma mobilização online no Dia de Proteção às Florestas, no intuito de demonstrar que $60 \%$ dos biomas estão em risco e necessitam sair dessa condição. A campanha conquistou mais de 400 mil assinaturas, nos sites e nas ruas. A propagação da quantidade de assinantes cresce na medida em que se propaga na rede informações sobre a inércia do Poder Público brasileiro para adotar medidas eficientes em relação à preservação das Florestas (GREENPEACE, 2012)

Nesse sentido, brasileiros de todas as regiões unem-se para atingir a cota de 1 milhão de assinaturas e levar um projeto de lei de iniciativa popular até o Congresso, tal qual feito com o "Ficha Limpa.". Por isso, o Greenpeace pede para que as pessoas doem suas contas nas redes sociais para divulgar e compartilhar o abaixo-assinado, e estimulem suas redes de contato a darem sua assinatura.

O ciberativismo, incitado pela ONG, em prol das Florestas, entretanto, não se restringe tão-somente à participação de brasileiros. É preciso lembrar que o movimento ambientalista, sobretudo o que desenvolve ações planejadas por meio da Internet, tem o condão de produzir impacto global. Nessa ótica, pessoas de todo o planeta podem ajudar na campanha das Florestas e nas demais ações encabeçadas pelo Greenpeace tornandose potenciais agentes que,com uma simples assinatura na petição, fazem, em tempo real, pressão sobre os Estados e sobre as Organizações Internacionais.

De modo similar ao Greenpeace, funciona a comunidade virtual denominada Avaaz, que não possui a natureza jurídica de ONG.

\begin{abstract}
O Avaaz atua como um megafone para chamar atenção para novas questões; como um catalisador para canalizar as preocupações públicas dispersas em uma única campanha específica e concentrada; como um carro de bombeiros que corre para oferecer uma rápida reação a uma emergência súbita e urgente; ou como uma célula-tronco de ativismo que cresce na forma mais adequada para preencher alguma necessidade urgente. (AVAAZ, 2012)
\end{abstract}

A proposta da entidade consiste em centralizar numa única equipe de atuação mundial a missão de trabalhar com qualquer questão de interesse público, de modo a estruturar com agilidade, flexibilidade e foco essas questões. Para tanto, são definidas, anualmente, as prioridades gerais através de pesquisas entre todos os membros que fazem parte da organização. Em 2012, as mudanças climáticas e o meio ambiente foram 
elencados entre as cinco prioridades que vão ensejar as campanhas do ano, igualandose, com o percentual de $67.68 \%$, à preocupação com a corrupção política.

Definidas as prioridades, a comunidade se mobiliza por meio de petições virtuais, protestos, financiamento de campanhas, telefonemas e envio de emails a governos (AVAAZ, 2012). Todas essas ações são organizadas virtualmente, o que oportuniza a difusão global do movimento e a soma de milhões de pequenas ações individuais, acarretando grandes impactos.

O Avaaz, ainda, criou um novo site que encoraja as pessoas a criarem suas próprias campanhas usando as ferramentas de petições online da Avaaz. Tal fato permite que pessoas ao redor do mundo sejam precursoras de iniciativas que alcancem vitórias em âmbito local, nacional e internacional.

O resultado desse trabalho, que une cidadãos de todos os continentes em torno de uma preocupação comum, foi expressivo na seara ambientalista. A campanha "Salve os Oceanos!", por exemplo, trouxe resultados que não se limitaram a meras manifestações de indignação nas redes sociais. No momento anterior à consulta pública, realizada no Reino Unido para criar a maior área de proteção marinha do mundo nas Ilhas Chagos, membros da Avaaz contribuiram com mais de $85 \%$ das respostas que deram apoio à criação da zona protetiva.

Do mesmo modo a organização motivou a assinatura, via petição online, de mais de 230.000 pessoas, em menos de 5 dias, com o propósito de pressionar o governo britânico a banir a pesca comercial e realizar um trabalho junto à população local para proteger os corais e o futuro dos oceanos.(AVAAZ, 2012).

Em face dessa realidade, o Reino Unido anunciou que pretende dobrar a área total de proteção dos oceanos com uma nova zona de conservação maior do que a Alemanha e Itália juntas. Ainda, o ministro de relações exteriores mencionou, em seu discurso, que foram "mais de 221.000 respostas coordenadas pela Avaaz, vindas de 223 países". (AVAAZ, 2012)

Dessa maneira, é possível contemplar que nas duas espécies de entidade, tanto o Avaaz quanto o Greenpeace possuem um modelo de mobilização que tem o ciberespaço como âncora. Tal modelo possibilita unir milhares de ações individuais pequenas que, conjugadas, transformam-se numa poderosa força coletiva. "Com a migração para a $W e b$, as entidades aderem à comunicação em tempo real, sem centros fixos de 
III SEMINÁRII ECDLOGIA

POLÍTICA

enunciação. A cada nó, incorporam-se novos usuários, os quais se convertem, potencialmente, em produtores e emissores de informações, em condições de serem consumidas a todo instante." (MORAES, 2001).

Enquanto outros grupos da sociedade civil valem-se de nichos locais e estratégias de atuação tradicionais e pouco flexíveis para atingir o seu intento, os movimentos sociais ambientalistas, a exemplo da análise realizada com as duas organizações globais mais populares que militam em favor do meio ambiente, reconhecem na Internet uma aliada indispensável para propagar informações e recrutar apoiadores que lutem por reivindicações relativas ao meio ambiente, as quais tocam a todos os seres humanos.

\section{CONSIDERAÇÕES FINAIS}

A forma como o homem interage com o meio ambiente é uma preocupação latente dos ativistas ambientais há mais de quatro décadas. Dentre os principais agentes que exigem uma nova forma de relação com o meio ambiente e que possuem uma postura firme de atuação e reivindicação por essa pauta, estão as organizações não governamentais e algumas comunidades globais que se organizam virtualmente.

Com o advento das novas tecnologias de informação e interação, as ONGs, em sua maioria, hoje percebem a necessidade de utilizar as facilidades proporcionadas pela $W e b$ na estruturação de campanhas e desenvolvimento de iniciativas em prol do meio ambiente. Com um baixo custo, alcance global e instantâneo das notícias e sem a necessidade de concessão do poder governamental, a Internet não só conecta, como agrega milhões de indivíduos em torno de preocupações e reivindicações ambientais.

O potencial de articular forças singulares que, unidas, formam contundentes coalizões, é bastante aproveitado pelas duas maiores entidades do planeta que incluem o meio ambiente no cerne de suas preocupações. A primeira delas - o Greenpeace - é uma organização não governamental que luta, especificamente, em benefício das causas ambientalistas. A segunda - o Avaaz - é uma comunidade global que organiza campanhas virtuais, principalmente através do fomento às petições online.

Observa-se que as campanhas promovidas virtualmente pelas duas organizações têm obtido resultados efetivos. O sucesso das iniciativas e petições do Greenpeace e do 


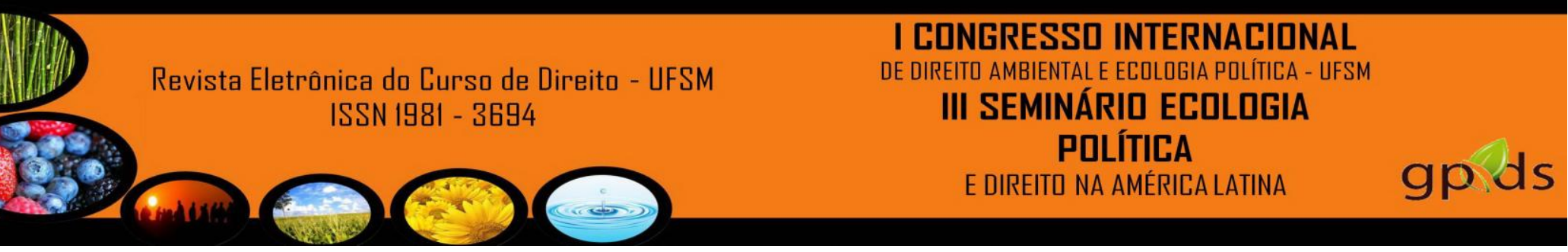

Avaaz é atribuído à capacidade de mobilização da opinião pública através do instrumental da Internet, que, em poucos segundos, transforma em global um acontecimento que, na visão superficial das mídias tradicionais, seria considerado como local.

Assim, o ciberativismo ambiental é hoje uma importante ferramenta na luta em favor do meio ambiente na medida em que possui uma força ímpar de conectar pessoas do mundo todo em torno de um objetivo comum. Igualmente, tal modalidade de ativismo concretiza uma ideia de participação democrática, pois permite que qualquer pessoa do mundo possa ser remetente ou destinatária de uma mensagem de cidadania, que busca transformar, enquanto for possível, o violento relacionamento que o homem vem mantendo com o restante da natureza.

\section{REFERÊNCIAS BIBLIOGRÁFICAS}

AVAAZ, 2012. Disponível em:< http://www.avaaz.org/po/about.php/>. Acesso em: 15 ago. 2012

2012

2012. Disponível em: <http://avaaz.org/en/sept21_hub/>. Acesso em 16 ago.

BARBROOK, Richard. Cyber-communism: how the Americans are superseding capitalism in cyberspace. In: Science in Culture, v. 9, n. 1, 2000, p. 5-40.

CASTELLS, Manuel. O poder da identidade. São Paulo: Paz e Terra, 2010.

ECODESENVOLVIMENTO, 2011. Disponível em: <http://www.ecodensenvolvimento.org/ posts/20122/julho/internet-propaga-e-fortaleceativismo-ambiental/>. Acesso em: 24 ago. 2012.

GREENPEACE, 2012. Disponível em: <http://www.greenpeace.org/brasil/>. Acesso em: 23 ago. 2012.

HANNIGAN, John. Sociologia ambiental. Petrópolis, RJ: Vozes, 2009.

LEÃO, Márcia Brandão Carneiro.O papel das ONGs- organizações não governamental na formação do direito internacional do meio ambiente. Dissertação ( Mestrado em Direito Ambiental)- São Paulo: Fac. de Direito da USP, 2002.

LEFF, Enrique. Saber ambiental: Sustentabilidade, racionalidade, complexidade, poder. Rio de Janeiro: Vozes, 2007. 
